\title{
(6) OPEN ACCESS \\ Millennium Development Goal 5 and adolescents: looking back, moving forward
}

\author{
Joshua P Vogel, ${ }^{1}$ Cynthia Pileggi-Castro, ${ }^{2,3}$ Venkatraman Chandra-Mouli, ${ }^{1}$ \\ Vicky Nogueira Pileggi, ${ }^{2,3}$ João Paulo Souza, ${ }^{3,4}$ Doris Chou, ${ }^{1}$ Lale Say ${ }^{1}$
}

${ }^{1}$ UNDP/UNFPA/UNICEF/WHO/ World Bank Special Programme of Research, Development and Research Training in Human Reproduction (HRP), Department of Reproductive Health and Research, World Health Organization, Geneva, Switzerland

${ }^{2}$ Department of Paediatrics, Ribeirão Preto Medical School, University of São Paulo, Ribeirão Preto, SP, Brazil ${ }^{3}$ GLIDE Technical Cooperation and Research, Ribeirão Preto, SP, Brazil

${ }^{4}$ Department of Social Medicine, Ribeirão Preto Medical School, University of São Paulo, Ribeirão Preto, SP, Brazil

\section{Correspondence to} Dr Joshua Vogel, Department of Reproductive Health and Research, World Health Organization, Avenue Appia 20, Geneva 1205, Switzerland; vogeljo@who.int

Received 12 August 2014 Accepted 31 October 2014

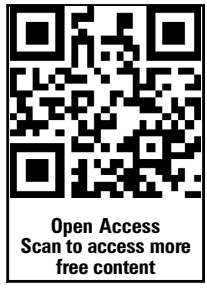

CrossMark

To cite: Vogel JP, PileggiCastro C, Chandra-Mouli V, et al. Arch Dis Child 2015;100(Suppl 1):s43-s47.

\section{ABSTRACT}

Since the Millennium Declaration in 2000, unprecedented progress has been made in the reduction of global maternal mortality. Millennium Development Goal 5 (MDG 5; improving maternal health) includes two primary targets, $5 \mathrm{~A}$ and $5 \mathrm{~B}$. Target $5 \mathrm{~A}$ aimed for a $75 \%$ reduction in the global maternal mortality ratio (MMR), and $5 \mathrm{~B}$ aimed to achieve universal access to reproductive health. Globally, maternal mortality since 1990 has nearly halved and access to reproductive health services in developing countries has substantially improved. In setting goals and targets for the post-MDG era, the global maternal health community has recognised that ultimate goal of ending preventable maternal mortality is now within reach. The new target of a global MMR of $<70$ deaths per 100000 live births by 2030 is ambitious, yet achievable and to reach this target a significantly increased effort to promote and ensure universal, equitable access to reproductive, maternal and newborn services for all women and adolescents will be required. In this article, as we reflect on patterns, trends and determinants of maternal mortality, morbidity and other key MDG5 indicators among adolescents, we aim to highlight the importance of promoting and protecting the sexual and reproductive health and rights of adolescents as part of renewed global efforts to end preventable maternal mortality.

\section{GLOBAL PROGRESS ON MILLENNIUM DEVELOPMENT GOAL 5}

The latest global maternal mortality estimates have demonstrated a $45 \%$ reduction in the global average maternal mortality ratio (MMR) ${ }^{1-4}$ compared with 1990 levels, from 380 deaths per 100000 live births (1990) to 210 deaths per 100000 live births (2013; figure 1). ${ }^{2}$ Furthermore, the average annual rate of reduction is accelerating, from $-2.2 \%$ (for the period $1990-2005$ ) to $-3.3 \%$ (for the period 2005-2013). ${ }^{2}$ Eleven countries have already reached their Millennium Development Goal (MDG) 5A maternal mortality targets, and a further 63 countries have made substantial progress, achieving an average annual decline of $-2.0 \%$ in 1990 to $-5.5 \%$ in $2013 .^{2}$ While other social, demographic and economic trends (such as improved education, delayed childbirth and greater economic opportunities) have contributed to maternal health gains in many countries, ${ }^{5}$ marked improvements in quality of and access to reproductive and maternal health services globally as part of the MDG initiative have had a substantial impact on reducing maternal deaths over the past two decades.

\section{HOW IS MDG5 MEASURED?}

Global progress on MDG5 is measured through six global indicators that were selected through international consultative processes (summarised in table 1), including the MMR, the proportion of births attended by skilled personnel, the adolescent birth rate, the contraceptive prevalence rate, antenatal care coverage and unmet need for family planning. ${ }^{1}$ For the period 1990-2012, in all developing countries, the skilled birth attendance rate increased from $56 \%$ to $68 \%$ and antenatal care coverage (four or more visits by a skilled provider) has increased from $37 \%$ to $52 \% .^{1}$ The unmet need for contraceptives has dropped from $16 \%$ to $12 \%$ and the contraceptive prevalence has risen from $52 \%$ to $63 \% .^{1}$ Globally, rates of adolescent pregnancy appear to be declining over time-the adolescent birth rate (number of births to women aged 15-19 years, per 1000 women) decreased from 64 per 1000 in 1990 to 54 per 1000 in $2011 .^{1}$ An estimated 16 million adolescents aged 15-19 years give birth every year. ${ }^{1}$ While data on childbearing girls below the age of 15 years is scarce, a recent review of birth rates among girls aged 12-15 years in low-resource countries estimated that as many as 2.5 million births occur each year to girls under 16 years of age, up to $50 \%$ of which occur in girls under 15 years of age. ${ }^{6}$

\section{ADOLESCENCE AND PREGNANCY GLOBALLY}

The number of adolescents (defined as those between the ages of 10 and 19 years) currently living worldwide is estimated at $18 \%$ of the world population. ${ }^{7}$ This proportion varies between regions, accounting for $12 \%$ of the population in developed countries and reaching $23 \%$ of the total population in the leastdeveloped countries. ${ }^{7}$ While this proportion has reduced over time worldwide (due to more generalised improvements in survival across age groups), in sub-Saharan Africa it has increased, a trend that is predicted to continue. ${ }^{7}$ The absolute number of adolescents living worldwide has steadily risen-there is currently an estimated 1.2 billion boys and girls worldwide, $90 \%$ of whom are living in developing countries. $^{7}$

The proportion of adolescent girls (15-19 years old) who are married or in a union in developing countries (excluding China) is $22 \% .^{7}$ Approximately $11 \%$ of global births occur in adolescent mothers, with $95 \%$ occurring in developing countries. ${ }^{8}$ Half of the world's adolescent births occur in just seven countries (India, Nigeria, Democratic Republic of Congo, Brazil, Bangladesh, China and Ethiopia). ${ }^{9}$ In developing countries, evidence suggests that most births to adolescent women occur within marriages 


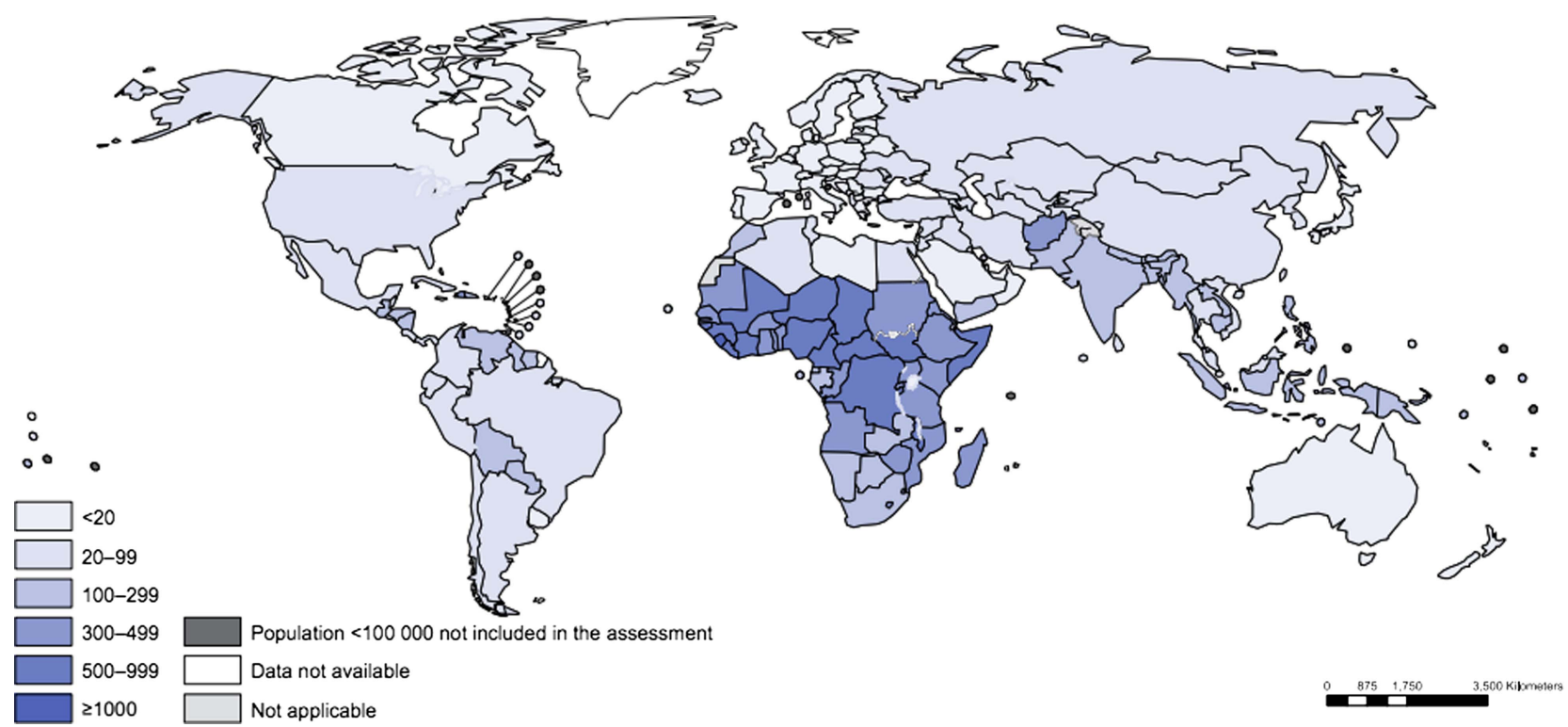

Figure 1 Map with countries by category according to their maternal mortality ratio (MMR, death per 100000 live births), 2013 (reprinted with permission from ref. 2). The boundaries and names shown and the designations used on this map do not imply the expression of any opinion whatsoever on the part of the WHO concerning the legal status of any country, territory, city or area or of its authorities or concerning the delimitation of its frontiers or boundaries. Dotted lines and dashed lines on maps represent approximate border lines for which there may not yet be full agreement.

and are wanted. ${ }^{9}$ However, these figures must be interpreted with caution due to considerable international variation-in many countries, a significant proportion of adolescent pregnancies are neither planned nor wanted. Furthermore, while a pregnancy may be wanted by an adolescent's community, family or partner, the individual adolescent may not wish to become pregnant and may have been pressured into pregnancy.

\section{FACTORS INFLUENCING ADOLESCENT PREGNANCY}

A range of factors have been implicated in how and why adolescent pregnancies occur, and while many adolescents may wish to fall pregnant, many pregnancies occur in the context of human rights violations such as child marriage, coerced sex or sexual abuse..$^{10}$ Broader socioeconomic factors, such as poverty, lack of education and limited economic opportunities for girls may also contribute to adolescent pregnancy rates. ${ }^{9}$ Other factors, including rurality, ethnicity and cultural norms have also been associated with higher rates of adolescent pregnancies in some countries. ${ }^{9}{ }^{11}$ Furthermore, a lack of reproductive healthcare services for adolescents (particularly a lack of contraceptive education and affordable, available contraceptive commodities) means contraceptive use among married and unmarried adolescents is generally low in developing regions, ${ }^{9}{ }^{12}$ even while contraceptive use in women of reproductive age appears to be increasing globally. ${ }^{1}$

\section{RISKS OF ADOLESCENT PREGNANCY}

Adolescent pregnancy, especially for younger adolescents, can carry increased risks of a range of pregnancy and childbirth complications due to underlying biological factors, such as gynaecological immaturity and incomplete pelvic growth. However, risks of adverse outcomes among pregnant adolescents can be further magnified by a higher prevalence of risk factors compared with older women, such as malnutrition, smoking, substance abuse, anaemia, malaria, HIV/AIDS and sexually transmitted infections. ${ }^{9}{ }^{13}$ In addition, of the estimated

Table 1 Trends in Millennium Development Goal 5 Indicators, developing regions only*

\begin{tabular}{|c|c|c|c|}
\hline & 1990 & 2000 & $2012 t$ \\
\hline $\begin{array}{l}\text { Maternal mortality ratio } \\
\text { (maternal deaths per } 100000 \text { live births) }\end{array}$ & 380 & 330 & 210 (2013) \\
\hline Proportion of births attended by skilled health personnel (\%) & $56 \%$ & $57 \%$ & $68 \%$ \\
\hline $\begin{array}{l}\text { Contraceptive prevalence rate } £ \\
\text { (percentage of women who are using any method of contraception among women aged 15-49 years, married or in union) }\end{array}$ & $51.8 \%$ & $59.8 \%$ & $62.5 \%$ \\
\hline $\begin{array}{l}\text { Adolescent birth rate } £ \\
\text { (number of live births per } 1000 \text { adolescent women aged } 15-19 \text { years) }\end{array}$ & 63.7 & 56.1 & $54.3(2011)$ \\
\hline $\begin{array}{l}\text { Antenatal care coverage: } \\
\text { At least one visitๆ (\%) } \\
\text { At least four visits }(\%)\end{array}$ & $\begin{array}{l}65 \% \\
37 \%\end{array}$ & $\begin{array}{l}71 \% \\
44 \%\end{array}$ & $\begin{array}{l}83 \% \\
52 \%\end{array}$ \\
\hline $\begin{array}{l}\text { Unmet need for family planning } \ddagger \S \\
\text { (percentage of women who have an unmet need for family planning among women aged } 15-49 \text { years, married or in union) }\end{array}$ & $16.5 \%$ & $13.5 \%$ & $12.4 \%$ \\
\hline
\end{tabular}


22 million unsafe abortions (the fourth leading direct cause of maternal deaths worldwide) occurring worldwide in 2008, $15 \%$ were in adolescents aged 15-19 years. ${ }^{14}{ }^{15}$ Adolescents may be disadvantaged in maintaining a healthy pregnancy, through poorer health education, inadequate access to antenatal care, skilled birth attendance or other healthcare services, or the inability to afford the financial costs of pregnancy and childbirth (including transport, admission, skilled birth attendance and/or commodities). This confluence of intrinsic and extrinsic risk factors that pregnant adolescents may experience can increase the risk of mortality and severe morbidity during pregnancy, childbirth and the postpartum period. However, findings from observational studies are often conflicting and it is difficult to establish whether these increased risks are due to biological factors, socioeconomic factors, inequities of availability and access to maternity care services, regional variations in adolescent health or circumstances, or a combination of these.

\section{MATERNAL MORTALITY}

Rates of maternal mortality from young adolescence to advanced maternal age have been described as the 'J-shaped' curve, where there are higher risks of maternal mortality associated with adolescence, a nadir at ages 20-29 years, with steadily increasing risk of death beyond the age of 30 years. ${ }^{16}$ A recent systematic review of data from 144 countries demonstrated this pattern, although the increased MMR in adolescents aged $15-19$ years $(260$ per 100000$)$ compared with women aged $20-24$ years $(190$ per 100000$)$ was somewhat less than reported previously. ${ }^{17-19}$ Despite reductions in maternal deaths globally, maternal mortality has been the second leading cause of death among adolescent girls (15-19 years old) worldwide since the year $2000 .{ }^{20} \mathrm{~A}$ systematic review by Patton et $a l^{21}$ found that of the estimated 2.6 million deaths occurring in young people aged 10-24 years worldwide in 2004, maternal conditions accounted for $15 \%$ of all female deaths.

While findings are often inconsistent across studies, there is evidence to suggest that pregnant adolescents are at higher risk of several maternal morbidities, with the youngest adolescents generally at the highest risk. A series of reviews of observational studies on the risk of adverse health outcomes in adolescents compared with older mothers reported likely higher risks of postpartum haemorrhage, obesity, mental illnesses and premature death in adolescent mothers. ${ }^{9} 19$ 22-27

Three studies of sub-Saharan African women with obstetric fistulae reported that $35 \%-40 \%$ of these women first developed the condition as adolescents, ${ }^{28-30}$ In a multicountry analysis of the WHO Multi-Country Survey on Maternal and Newborn Health of over 124000 women under the age of 24 years, Ganchimeg et $a l^{31}$ reported significantly higher adjusted odds of eclampsia, puerperal endometritis and systemic infections among all adolescent age groups, compared with women aged 20-24 years. Evidence of the association between adolescence and adverse neonatal outcomes is more conclusive. A majority of observational studies included in a series of reviews found higher risks of newborn and infant mortality, preterm birth, low birth weight, malformations and asphyxia among adolescent mothers. ${ }^{9} 19$ 32-35

Pregnancy can also potentially affect an adolescent mother's longer term social and economic circumstances in some settings, particularly where pregnancy occurs outside of a formal union. This can contribute to difficulty in completing education, social isolation, lack of family support, poorer employment opportunities and continuing poverty. ${ }^{36}$

\section{ADOLESCENTS AND THE MDG-5 INDICATORS}

While the MDG-5 indicators have all shown generalised improvements over the past 15 years, ${ }^{1}$ there is a lack of stratification of these indicators by age group. Consequently, it cannot be assumed that global trends in maternal mortality reduction and improved access to essential reproductive health services (such as skilled birth attendance, antenatal care and contraceptives) are mirrored in adolescent populations. Similar limitations have been identified when using population representative survey data sets such as Demographic and Health Surveys (DHS) and Multiple Indicator Cluster Surveys to understand health outcomes of adolescents, including exclusion of younger adolescents and/or unmarried women from surveys, omission of indicators on prevalence and causes of maternal mortality and morbidity and lack of age disaggregation. ${ }^{37}$ However, available evidence suggests that substantial inequities exist in the use of reproductive health services by adolescents in many countries, compared with older women.

Some studies from lower income countries have demonstrated significantly lower antenatal care participation among adolescents compared with older women; ${ }^{38-40}$ however, others have not found any difference. ${ }^{41} 42$ A WHO-led DHS analysis showed that skilled birth attendance and facility attendance rates for childbearing adolescents is significantly lower compared with older mothers in some lower income countries, but this was not consistent across all countries. ${ }^{9}$ A related DHS analysis by Guttmacher Institute and the International Planned Parenthood Foundation reported that the proportion of women under 20 years of age whose most recent birth was in a health facility ranged from $12 \%$ (Ethiopia, 2011) to $87 \%$ (Rwanda, 2010 ) in Africa, 16\% (Bangladesh, 2007) to $48 \%$ (Viet Nam, 2002) in South/Southeast Asia and 60\% (Guatemala, 2008) to 99\% (Dominican Republic, 2007) in Latin America and the Caribbean. ${ }^{43}$ A DHS analysis of 61 lower income countries that examined contraceptive use in young people found that among young married women unmet need for contraceptives was high (ranging from $8.0 \%$ to $45.7 \%$ between countries) and generally even higher among young unmarried women (ranging from $7.3 \%$ to $69.5 \%$ between countries). ${ }^{44}$ They also reported that while unmet need for contraceptives (for women aged 15-24 years) appears to have declined over time (suggesting improvements in access), it still remains substantial, particularly in West and Central Africa. ${ }^{44}$

\section{FUTURE EFFORTS TO REDUCE PREGNANCY AND MATERNAL MORTALITY IN ADOLESCENTS}

With the substantial progress made over the MDG period, the end of preventable maternal death is now within reach. The sustainable development goals initiative that will take the place of the MDGs (for the period 2015-2030) is currently being developed, and as part of this new global effort, the international maternal health community (including governments, international agencies and donors) have reached consensus on a new global target of an MMR of $<70$ by $2030 .{ }^{4}$ To reach this global target, by 2030 no country should have an MMR $>140$ deaths per 100000 live births. ${ }^{4}$ The ending preventable maternal mortality (EPMM) initiative has emphasised the importance of reducing gender inequities and promoting equitable access of women and girls to quality reproductive health services (including maternal health) to reduce maternal mortality. ${ }^{4}$ National efforts to reduce maternal deaths should therefore by necessity consider key subpopulations, including adolescents. Strengthening health systems to address the needs and priorities of women and adolescent girls is a 
key strategic objective of the EPMM initiative as is the need for improved measurement systems and data quality that can better address data gaps around adolescent health. ${ }^{4}$

Global efforts to reduce adolescent pregnancy and prevent maternal and infant morbidity and mortality among adolescents need to systematically and comprehensively address the complex range of social, economic and cultural pressures that adolescent girls may experience in their communities. The WHO guidelines 'preventing early pregnancy and poor reproductive outcomes among adolescents in developing countries' published in 2011 identified a range of interventions to prevent early pregnancy, including strategies to reduce adolescent marriage and pregnancies, increase contraceptive use, reduce coerced sex and unsafe abortion and increase the use of maternity healthcare services. ${ }^{8}$ Programmatically, these interventions require a multilevel approach, involving a range of stakeholders (particularly adolescents themselves) and will need to be adapted to local contexts. The guidelines also highlight the urgent need for legal reform to support adolescent health programmes, especially in the prevention of early marriage, increasing contraceptive use and reducing coerced sex and unsafe abortion. ${ }^{10}$

A considerable research agenda for improving the reproductive health of adolescents remains to be achieved. There is a lack of adolescent-specific data (including both younger and older adolescents) on the use of and access to sexual and reproductive health resources that must be addressed, to better inform adolescent-specific health policies. Research is needed to better understand the barriers to delivering reproductive health care to adolescents, to optimise implementation of reproductive health programmes. Research is needed to ensure that these programmes address the social determinants of adolescent reproductive health described above. Furthermore, as identified both in the WHO guidelines ${ }^{8}$ and a recent WHO-led priority setting exercise, ${ }^{45}$ there is a growing recognition of the need for research on improving implementation and scale-up of effective interventions and programmes for adolescents.

\section{CONCLUSION}

While the MDG initiative has resulted in a substantial reduction in global maternal mortality and broad improvements in access to reproductive health services and commodities globally, a considerable agenda remains unfinished. Adolescents particularly present challenges to the implementation and delivery of reproductive health programmes, due to the range of cultural, social, economic and health factors that can contribute to adolescent pregnancy and the associated risks of adverse outcomes. In the context of a rising numbers of adolescents living worldwide and the commencement of the new sustainable development goal initiative, the reproductive and maternal health community has a unique opportunity to better focus research and contextualise programme implementation with a more nuanced consideration of the social, cultural and other factors affecting the sexual and reproductive health and rights of adolescents. Putting the reproductive health needs and priorities of adolescents at the heart of efforts to strengthen health systems, promoting equitable access to services and improving data quality will help make the end of preventable maternal mortality a reality. Engaging adolescents in the development and implementation of reproductive health programmes will be essential to their long-term success.

Acknowledgements The authors would like to thank Dr Dina Khan for her input.

Contributors JPV, CP-C, JPS and VNP developed the concept for this article. JPV, CP-C, JPS and VNP wrote the initial draft with input from VC-M, DC and LS. All named authors contributed to the development of the final manuscript.

\section{Competing interests None.}

Provenance and peer review Commissioned; internally peer reviewed.

Open Access This is an Open Access article distributed in accordance with the Creative Commons Attribution Non Commercial (CC BY-NC 4.0) license, which permits others to distribute, remix, adapt, build upon this work non-commercially, and license their derivative works on different terms, provided the original work is properly cited and the use is non-commercial. See: http://creativecommons.org/ licenses/by-nc/4.0/

\section{REFERENCES}

1 United Nations. Millennium Development Goals Report 2014. New York: United Nations, 2014.

2 World Health Organization. Trends in Maternal Mortality: 1990 to 2013. Geneva: World Health Organization; 2013.

3 Bustreo F, Say L, Koblinsky M, et al. Ending preventable maternal deaths: the time is now. Lancet Global Health 2013;1:e176-7.

4 World Health Organization. Targets and strategies for ending preventable maternal mortality: consensus statement [Internet]. World Health Organization; 2014. http:/l www.who.int/reproductivehealth/publications/maternal_perinatal_health/ consensus-statement.pdf?ua= 1

5 Souza J, Tuncalp 0, Vogel JP, et al. Obstetric transition: the pathway towards ending preventable maternal deaths. BJOG 2014;121(Suppl 1):1-4.

6 Neal S, Matthews Z, Frost M, et al. Childbearing in adolescents aged 12-15 years in low resource countries: a neglected issue. New estimates from demographic and household surveys in 42 countries. Acta Obstet Gynecol Scand 2012;91: 1114-18

7 UNICEF. Progress for children [Internet]. New York: UNICEF, 2012. http://www. unicef.org/media/files/PFC2012_A_report_card_on_adolescents.pdf

8 World Health Organization. WHO guidelines on preventing early pregnancy and poor reproductive outcomes among adolescents in developing countries. Geneva: World Health Organization, 2011.

9 World Health Organization. Position paper on mainstreaming adolescent pregnancy in efforts to make pregnancy safer [Internet]. Geneva: World Health Organization, 2010. http://www.who.int

10 Chandra-Mouli V, Camacho AV, Michaud P-A. WHO guidelines on preventing early pregnancy and poor reproductive outcomes among adolescents in developing countries. J Adolesc Health 2013;52:517-22.

11 Rani M, Lule E. Exploring the socioeconomic dimension of adolescent reproductive health: a multicountry analysis. Int Fam Plan Perspect 2004;30:110-17.

12 Chandra-Mouli V, McCarraher DR, Phillips SJ, et al. Contraception for adolescents in low and middle income countries: needs, barriers, and access. Reprod Health 2013;11:1.

13 Kalanda BFB, Verhoeff FHF, Chimsuku LL, et al. Adverse birth outcomes in a malarious area. Bull Entomol Res 2006;134:659-66.

14 Shah IH, Åhman E. Unsafe abortion differentials in 2008 by age and developing country region: high burden among young women. Reprod Health Matters 2012;20: 169-73.

15 Say L, Chou D, Gemmill A, et al. Global causes of maternal death: a WHO systematic analysis. Lancet Glob Health 2014;2:1-11.

16 Blanc AK, Winfrey W, Ross J. New findings for maternal mortality age patterns: aggregated results for 38 countries. PLOS ONE 2012;8:e59864-4.

17 Mallé D, Ross DA, Campbell OM, et al. Institutional maternal mortality in Mali. Int $J$ Gynaecol Obstet 1994;46:19-26.

18 Granja AC, Machungo F, Gomes A, et al. Adolescent maternal mortality in Mozambique. J Adolesc Health 2001;28:303-6.

19 Conde-Agudelo A, Belizan JM, Lammers C. Maternal-perinatal morbidity and mortality associated with adolescent pregnancy in Latin America: cross-sectional study. Am J Obstet Gynecol 2005;192:342-9.

20 World Health Organization. Health for the World's Adolescents: second chance in the second decade [Internet]. Geneva: World Health Organization, 2014. http:/l apps.who.int/adolescent/second-decade/files/1612_MNCAH_HWA_Executive_ Summary.pdf

21 Patton GC, Coffey C, Sawyer SM, et al. Global patterns of mortality in young people: a systematic analysis of population health data. Lancet 2008;374:881-92.

22 Kac G, Velásquez-Meléndez G, Valente JG. [Menarche, early pregnancy, and obesity in selected Brazilian women from a health care center in Belo Horizonte, Minas Gerais, Brazil]. Cad Saude Publica 2002;19(Suppl 1):S111-18.

23 Gigante DP, Rasmussen KM, Victora CG. Pregnancy increases BMI in adolescents of a population-based birth cohort. J Nutr 2005;135:74-80.

24 Eshbaugh EM. Predictors of depressive symptomatology among low-income adolescent mothers. Arch Womens Ment Health 2006;9:339-42.

25 Logsdon MC, Birkimer JC, Simpson T, et al. Postpartum depression and social support in adolescents. J Obstet Gynecol Neonatal Nurs 2005;34:46-54.

26 Henretta JC. Early childbearing, marital status, and women's health and mortality after age 50. J Health Soc Behav 2007;48:254-66.

27 Olausson PO, Haglund B, Weitoft GR, et al. Premature death among teenage mothers. BJOG 2004;111:793-9. 
28 Muleta M, Fantahun M, Tafesse B, et al. Obstetric fistula in rural Ethiopia. East Afr Med J 2007:84:525-33.

29 Holme A, Breen M, MacArthur C. Obstetric fistulae: a study of women managed at the Monze Mission Hospital, Zambia. BJOG 2007;114:1010-7.

30 Gessessew A, Mesfin M. Genitourinary and rectovaginal fistulae in Adigrat Zonal Hospital, Tigray, north Ethiopia. Ethiop Med J 2003;41:123-0.

31 Ganchimeg T, Ota E, Morisaki N, et al. Pregnancy and childbirth outcomes among adolescent mothers: a World Health Organization multicountry study. BJOG 2014;121(Suppl 1):40-8.

32 Chen X-K, Wen SW, Fleming N, et al. Teenage pregnancy and congenital anomalies: which system is vulnerable? Hum Reprod 2007;22:1730-5.

33 Chen $\mathrm{X}-\mathrm{K}$, Wen SW, Fleming $\mathrm{N}$, et al. Teenage pregnancy and adverse birth outcomes: a large population based retrospective cohort study. Int J Epidemiol 2007;36:368-73.

34 Gilbert W, Jandial D, Field N, et al. Birth outcomes in teenage pregnancies. J Matern Fetal Neonatal Med 2004;16:265-70.

35 Salihu HM, Sharma PP, Ekundayo OJ, et al. Childhood pregnancy (10-14 years old) and risk of stillbirth in singletons and twins. J Pediatr 2005;148:522-6.

36 McQueston K, Silverman R, Glassman A. Adolescent fertility in Low- and Middle-income countries: Effects and Solutions. Working Paper 295. [Internet]. Washington D.C.: Centre for Global Development, 2012. http://www.cgdev.org./ content/publications/1426175

37 Gray N, Azzopardi P, Kennedy E, et al. Briefing Paper: Achieving MDG 5 for adolescents in Asia and the Pacific: lessons for the delivery of reproductive health services. Part 1:
A review of available data in nine countries. Melbourne, Australia: Burnet Institute, on behalf of Compass, the Women"s and Children"s Health Knowledge Hub, 2010

38 Hidalgo LA, Chedraui PA, Chávez MJ. Obstetrical and neonatal outcome in young adolescents of low socio-economic status: a case control study. Arch Gynecol Obstet 2005;271:207-11.

39 Kongnyuy EJ, Nana PN, Fomulu N, et al. Adverse perinatal outcomes of adolescent pregnancies in Cameroon. Matern Child Health J 2008;12:149-54.

40 Goldenberg $\mathrm{P}$, Figueiredo MDCT, Silva $\mathrm{R}$, et al. Adolescent pregnancy, prenatal care, and perinatal outcomes in Montes Claros, Minas Gerais, Brazil. Cad Saude Publica 2005;21:1077-86.

41 Taffa N. A comparison of pregnancy and child health outcomes between teenage and adult mothers in the slums of Nairobi, Kenya. Int I Adolesc Med Health 2003:15:321-9.

42 Goonewardene IMR, Waduge RPKD. Adverse effects of teenage pregnancy. Ceylon Med J. 2005:50:116-20.

43 Anderson R, Panchaud C, Singh S, et al. Demystifying data: a guide to using evidence to improve young people's sexual health and rights. New York: Guttmacher Institute, 2013.

44 MacQuarrie K. Unmet need for family planning among young women: levels and trends. Rockville, Maryland, USA: USAID; 2014.

45 Hindin MJ, Christiansen CS, Ferguson BJ. Setting research priorities for adolescent sexual and reproductive health in low- and middle-income countries. Bull World Health Organ 2013;91:10-8. 